\title{
Requirements for Beneficial Electrochemical Restructuring: A Model Study on a Cobalt Oxide in Selected Electrolytes
}

\author{
Javier Villalobos, Diego González-Flores, * Roberto Urcuyo, Mavis L. Montero, \\ Götz Schuck, Paul Beyer, and Marcel Risch*
}

The requirements for beneficial materials restructuring into a higher performance oxygen evolution reaction (OER) electrocatalyst are still a largely open question. Here erythrite $\left(\mathrm{CO}_{3}\left(\mathrm{AsO}_{4}\right)_{2} \cdot 8 \mathrm{H}_{2} \mathrm{O}\right)$ is used as a Co-based OER electrocatalyst to evaluate its catalytic properties during in situ restructuring into an amorphous Co-based catalyst in four different electrolytes at $\mathrm{pH}$ 7. Using diffraction, microscopy, and spectroscopy, a strong effect in the restructuring behavior is observed depending of the anions in the electrolyte. Only carbonate electrolyte can activate the catalyst material, which is related to its slow restructuring process. While the catalyst turnover frequency (TOF) undesirably reduces by a factor of 28 , the number of redox active sites continuously increases to a factor of 56 , which results in an overall twofold increase in current of the restructured catalyst after 800 cycles. The activation is attributed to an adequate local order, a high Co oxidation state close to $3+$, and a high number of redox-active Co ions. These three requirements for beneficial restructuring provide new insights into the rational design of highperformance OER catalysts by electrochemical restructuring.

\section{Introduction}

The widespread use of renewable energy requires efficient energy storage solutions due to the fluctuating energy production from renewable sources such as sunlight or wind. A promising solution is the storage of chemical energy by water splitting into hydrogen and oxygen..$^{[1,2]}$ Complex kinetics make the oxygen evolution reaction (OER) one of the most considerable challenges for implementing water splitting as it requires high catalytic efficiency and stability under operating conditions. ${ }^{[3]}$

J. Villalobos, M. Risch

Nachwuchsgruppe Gestaltung des Sauerstoffentwicklungsmechanismus

Helmholtz-Zentrum Berlin für Materialien und Energie $\mathrm{GmbH}$

Hahn-Meitner Platz 1, Berlin 14109, Germany

E-mail: marcel.risch@helmholtz-berlin.de

D. González-Flores, R. Urcuyo, M. L. Montero

Centro de Investigación en Ciencia e Ingeniería de Materiales (CICIMA)

San José 11501 2060, Costa Rica

E-mail: diegoandres.gonzalez@ucr.ac.cr

The ORCID identification number(s) for the author(s) of this article can be found under https://doi.org/10.1002/aenm.202101737.

(C) 2021 The Authors. Advanced Energy Materials published by Wiley-VCH GmbH. This is an open access article under the terms of the Creative Commons Attribution License, which permits use, distribution and reproduction in any medium, provided the original work is properly cited.
For the use of carbon-based fuels as energy storage, near-neutral $\mathrm{pH}$ operating conditions are desirable to couple the anodic OER to the cathodic $\mathrm{CO}_{2}$ reduction reaction since $\mathrm{CO}_{2}$ enrichment of the electrolyte leads to $\mathrm{pH}$ values close to $7 .[4,5]$

Amorphous transition-metal oxides have shown outstanding catalytic properties at neutral $\mathrm{pH}^{[6-8]}$ Thanks to their unique atomic arrangement, these materials own structural flexibility and distinctively coordinated metal centers. ${ }^{[9-11]}$ Electrochemically, amorphous oxides can be obtained by electrodeposition ${ }^{[12-14]}$ or electrochemical restructuring ${ }^{[9,15-19]}$ of crystalline materials. The latter approach has improved catalytic activity compared to their crystalline variant in some cases, ${ }^{[0,10,12,20]}$ while this was not the case for other combinations of pristine materials and electrolytes. ${ }^{[21,22]}$ Wang et al. ${ }^{[23]}$ identified an optimal Co redox level for the activation of $\mathrm{LiCoO}_{2-x} \mathrm{Cl}_{x}$ by beneficial electrochemical restructuring in $1 \mathrm{~m} \mathrm{KOH}$. The requirements for beneficial electrochemical restructuring, particularly in neutral electrolytes, are still largely an open question. ${ }^{[18,24]}$

Among a wide range of amorphous transition-metal oxides, Co-containing oxides own particular properties, such as selfhealing, ${ }^{[25,26]}$ semiconductivity, ${ }^{[27-29]}$ and the possibility of hosting higher oxidation states, such as $\mathrm{Co}(\mathrm{IV}),{ }^{[8,30]}$ which has been proposed as part of the active site. ${ }^{[31]}$ Electrodes of Co-based oxides present overpotentials of $400-490 \mathrm{mV}$ at $10 \mathrm{~mA} \mathrm{\textrm {cm } _ { \text { geo } }}{ }^{-2}$

\author{
D. González-Flores, R. Urcuyo, M. L. Montero \\ Escuela de Química \\ Universidad de Costa Rica \\ San José 11501 2060, Costa Rica \\ D. González-Flores, R. Urcuyo \\ Centro de Electroquímica y Energía Química (CELEQ) \\ San José 11501 2060, Costa Rica \\ G. Schuck \\ Abteilung Struktur und Dynamik von Energiematerialien \\ Helmholtz-Zentrum Berlin für Materialien und Energie $\mathrm{GmbH}$ \\ Berlin 14109, Germany \\ P. Beyer \\ Fachbereich Physik \\ Freie Universität Berlin \\ Arnimallee 14, Berlin 14195, Germany
}

DOI: 10.1002/aenm.202101737 
with turnover frequencies (TOF) as high as $0.21 \mathrm{O}_{2} \mathrm{Co}^{-1} \mathrm{~s}^{-1}$ for $\mathrm{Co}\left(\mathrm{PO}_{3}\right)_{2}$ nanoparticles ${ }^{[32]}$ and Tafel slopes of $60-80 \mathrm{mV} \mathrm{\textrm {dec } ^ { - 1 }}$ (for layered $\mathrm{Co}$ oxides and $\mathrm{Co}_{3} \mathrm{O}_{4}$ ) in near-neutral pH (Table S1, Supporting Information). ${ }^{[31,33-35]}$ The local structure of the Co oxide differs depending on the cations and anions present in the electrodeposition electrolyte; for instance, the local order of the final Co oxide decreases as a function of the electrolyte in the order $\mathrm{CaCl}_{2}>\mathrm{KCl}>\mathrm{LiOAC}>\mathrm{KOAC}>\mathrm{KPi} .{ }^{[8]}$ The numbers of $\mathrm{Co}-$ Co scattering interactions at $2.8^{[36]}$ and $5.6 \AA^{[8]}$ were previously used to estimate the size of the ordered Co oxide fragments (also called clusters) by analysis of the extended X-ray absorption fine structure (EXAFS). ${ }^{[36-38]}$ Risch et al. ${ }^{[36]}$ identified an increase in current per Co with a number of Co-Co interactions at $2.8 \AA$ for restructured perovskite oxides, which suggests an optimal cluster size containing nine Co atoms, when compared to an earlier study on electrodeposited Co oxide. ${ }^{[8]}$ Additionally, Kwon et al. ${ }^{[39]}$ reported larger interlayer spacing and cluster size by variation of the electrolyte anions during the electrodeposition of Co oxides as follows: borate $(\mathrm{pH} 9.2)>$ methyl phosphate $(\mathrm{pH}$ 8.0) > phosphate ( $\mathrm{pH}$ 7.0). Thus, crystalline Co oxides are attractive starting materials for further enhancement by electrochemical restructuring into more active amorphous oxides.

In this study, we synthesized erythrite $\left(\right.$ Ery; $\left.\mathrm{Co}_{3}\left(\mathrm{AsO}_{4}\right)_{2} \cdot 8 \mathrm{H}_{2} \mathrm{O}\right)$ as a Co-based catalyst model to evaluate its catalytic properties during electrochemical restructuring into partially amorphous Co oxide in four different electrolytes at $\mathrm{pH}$ 7. The three electrolytes with clearly different restructuring behavior were chosen to track the conversion during cyclic voltammetry (CV) by diffraction, microscopy, and spectroscopy. We observed that the progress of the electrochemical restructuring with cycling strongly depended on the electrolyte anion. Only carbonate electrolyte activated the catalytic current over cycling due to a slow restructuring process. The final activated material showed an adequate cluster size, a high Co oxidation state, and high Co redox activity, which are essential features to enhance the catalytic activity. Hence, this work provides new insights into the requirements of beneficial electrochemical restructuring of Co-based materials.

\section{Results and Discussion}

\subsection{Electrochemical Restructuring of Ery in Selected Electrolytes}

Erythrite was chosen as a model system to study the effect of electrochemical restructuring on catalytic activity in selected neutral electrolytes with different anions. Pristine Ery is a crystalline material, a part of a group of isostructural minerals called vivianites. ${ }^{[40]}$ We synthesized it by a thermal process at $65{ }^{\circ} \mathrm{C}$, which assured crystal growth. Physical and chemical characterizations were carried out to confirm the formation of the Ery phase (Figure S1, Supporting Information). In the chemical structure of Ery, ${ }^{[41,42]}$ arsenate anions bind two positions of Co atoms: $\mathrm{Co}(1)$ on the hexacoordinated position and $\mathrm{Co}(2)$ bound via di- $\mu$-oxo(arsenate)-bridge (Figure 1 ; various structures in Figure S2 of the Supporting Information). Ery ${ }^{[43]}$ and other isostructural materials ${ }^{[12]}$ have been previously used as catalysts for OER. We have observed their trend to lose long-range order (commonly called amorphization) after voltage cycling under OER conditions. This transformation, i.e., electrochemical restructuring, promoted layered cobalt oxide formation, which

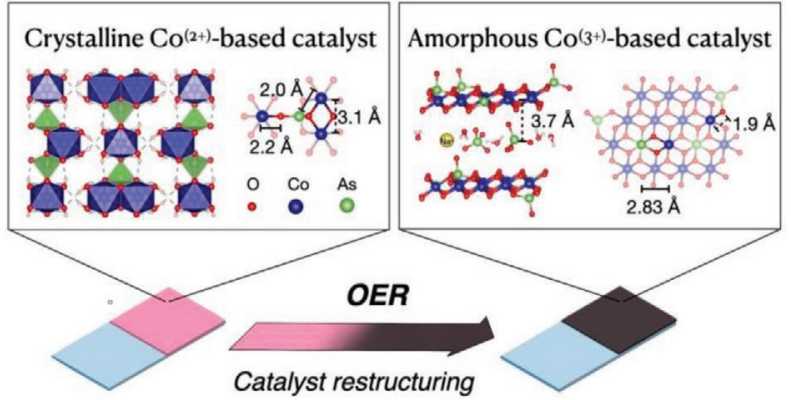

Figure 1. Diagram of the electrochemical restructuring of Ery. The crystalline Ery $\left(\mathrm{CO}_{3}\left(\mathrm{AsO}_{4}\right)_{2} \cdot 8 \mathrm{H}_{2} \mathrm{O}\right)$ layers are joined by hydrogen bonds. Arsenate binding in Ery, Co-As, and $\mathrm{Co}-\mathrm{Co}$ distances are shown. The amorphous layered Co oxide structure and distances of different binding modes from arsenate anions into the layer and at the border are shown. Ions and water molecules are present in the interlayer space at a distance of about $3.7 \AA$ from the Co atoms of the layer (fragments).

has significantly different interatomic distances as compared to Ery (Figure 1). For instance, the $\mathrm{Co}(2)-\mathrm{Co}(2)$ distance changed from $3.1 \AA$ in Ery to about $2.8 \AA$ after restructuring (Figure 1).

Ery deposited on fluorine-doped tin oxide (FTO) glass showed clearly different trends during CV in four different electrolytes at pH 7 (electrochemical protocol in Table S2 of the Supporting Information). The used anions were $0.1 \mathrm{M}$ of borate, phosphate, carbonate, and arsenate, resulting in the restructured catalysts Ery- $\mathrm{BO}_{3}$, Ery $-\mathrm{PO}_{4}$, Ery- $\mathrm{CO}_{3}$, and Ery- $\mathrm{AsO}_{4}$, respectively (Figure 2; Figure S3, Supporting Information). We used a high number of cycles (here 800 cycles), a high upper potential limit (2.1 V vs reversible hydrogen electrode (RHE)), and a high sweep speed $\left(100 \mathrm{mV} \mathrm{s}^{-1}\right)$ as typical for stability, restructuring, or activation studies. ${ }^{[14,44-47]}$ The maximum current density, $j_{\max }$ (at $2.1 \mathrm{~V}$ vs RHE), was comparable among all different electrolytes during the first cycles, i.e., it is mainly that of the as-synthesized Ery. Yet, $j_{\max }$ continuously increased in carbonate electrolyte, whereas, in phosphate and borate electrolytes, it rose during the first 200-300 cycles, after which it started decreasing. The current density after the OER onset remained mostly unaffected in arsenate electrolyte, indicating an equilibrium between the structural arsenate anions in Ery and the electrolyte. While there are minor shifts in the CV curves in Figure 2d, e.g., $20 \mathrm{mV}$ between the 2 nd and 800th cycles at $2 \mathrm{~mA} \mathrm{~cm}^{-2}$, these are smaller than the potential shifts of around $30 \mathrm{mV}$ at $2 \mathrm{~mA} \mathrm{~cm}{ }^{-2}$ for repeated experiments (Figure S3, Supporting Information). Thus, we conclude the absence of significant catalytic changes on Ery- $\mathrm{AsO}_{4}$. All trends mentioned above were reproducible in three trials (Figure S4, Supporting Information).

In addition to catalytic changes, increased broad redox peaks were observed with cycling, which had previously been associated with the number of redox-active metal ions ${ }^{[8,13]}$ and in crystalline materials with the electrochemical restructuring to an amorphous material. ${ }^{[9,12,36,43]}$ The redox-active metal ions can be quantified by integrating the reductive currents in the $\mathrm{CV}$ resulting in an electroredox charge (ERC). In Co-based catalysts, the ERC correlates with the redox activity of Co during the catalytic reaction assuming a single electron transfer, as detailed elsewhere. ${ }^{[8,12,13]}$ ERC trends over cycling were estimated in different electrolytes (Figure S5, Supporting Information). The initial Ery phase had an ERC of $0.1 \mathrm{mC}$ 

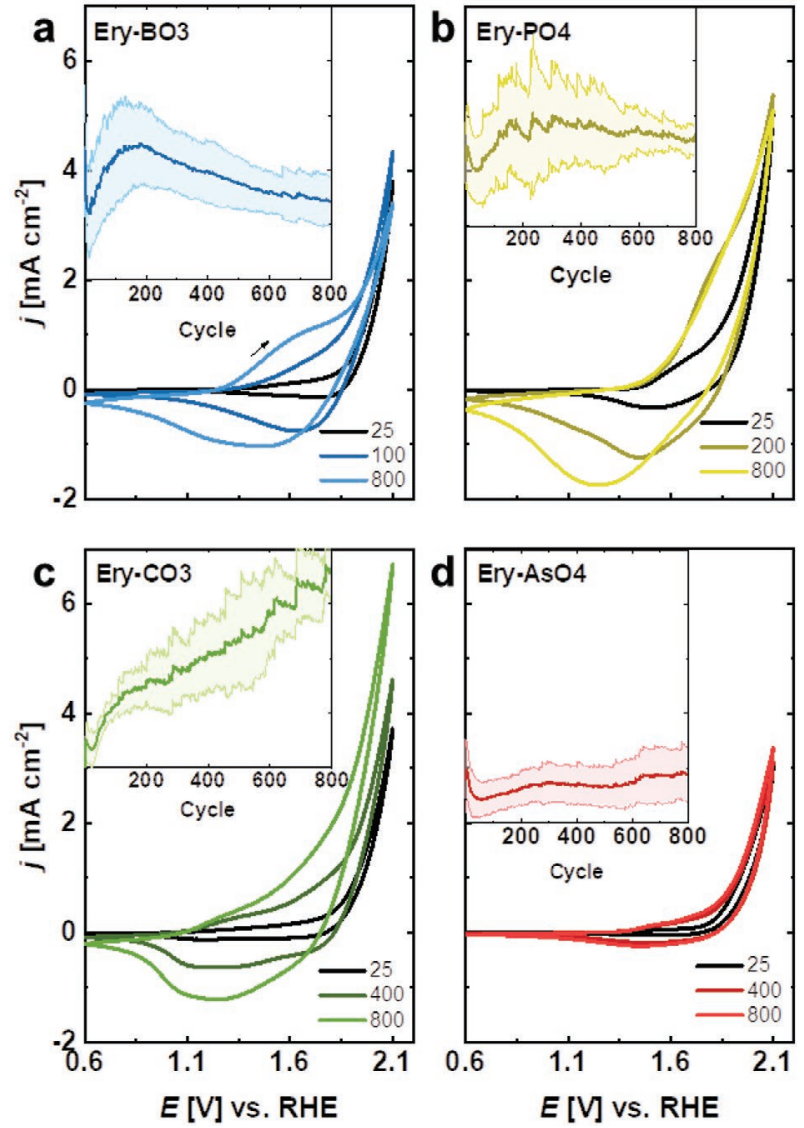

Figure 2. Series of CV performed on an Erythrite-deposited FTO glass in different electrolytes at $\mathrm{pH} 7$ and a concentration of $0.1 \mathrm{~m}$ : a) borate, b) phosphate, c) carbonate, and d) arsenate. 800 cycles were performed with a sweep speed of $100 \mathrm{mV} \mathrm{s}^{-1}$ and $85 \%$ iR compensation, of which the 25th, 400th, and 800th cycles are shown. The arrows indicate the scan direction. The insets show the $j_{\max }$ trends (at $E=2.1 \mathrm{~V}$ vs $\mathrm{RHE}$ ) as a function of cycling. The light-colored areas represent the standard deviation of three different samples. The FTO substrates were coated with an equivalent mass of Ery $(0.4 \mathrm{mg})$ on a $1 \mathrm{~cm}^{2}$ area. Dataset in ref. [48].

$\left(\right.$ Ery $-\mathrm{BO}_{3}$, Ery $\left.-\mathrm{AsO}_{4}\right)$ or $0.3 \mathrm{mC}\left(\right.$ Ery $-\mathrm{PO}_{4}$, Ery $\left.-\mathrm{CO}_{3}\right)$ during the second cycle. Ery- $\mathrm{BO}_{3}$ reached a steady state at cycle 300 ( $\mathrm{ERC}=11.4 \mathrm{mC}, 54 \times$ increase), whereas Ery- $\mathrm{PO}_{4}$ and Ery $-\mathrm{CO}_{3}$ increased constantly over 800 cycles and did not reach a steady state; the final ERC values are $15.5 \mathrm{mC}(57 \times$ increase) and $16.0 \mathrm{mC}(56 \times$ increase), respectively. Similar to the activity trends, the changes for Ery- $\mathrm{AsO}_{4}$ were small (ERC $=3.3 \mathrm{mC}$, $25 \times$ increase, after 800 cycles).

The potential of the maximum of the reductive (i.e., cathodic) peak significantly differed depending on the electrolyte. The initial peak potentials were around $1.45 \mathrm{~V}$ versus RHE in the four electrolytes, i.e., that of pristine Ery. They changed to $1.42 \mathrm{~V}$ versus RHE in Ery- $\mathrm{PO}_{4}, 1.65 \mathrm{~V}$ versus RHE in Ery- $\mathrm{BO}_{3}$, and $1.34 \mathrm{~V}$ versus RHE in Ery- $\mathrm{CO}_{3}$ after 800 cycles (Figure S6, Supporting Information). Risch et al. ${ }^{[31]}$ reported similar redox peak positions for CoCat (abbreviation for Co-catalyst, electrodeposited in phosphate buffer, $\mathrm{KPi}, \mathrm{pH} 7)$. They assigned the midpoint potential between the anodic and cathodic redox peaks at $1.42 \mathrm{~V}$ versus $\mathrm{RHE}$ to the $\mathrm{Co}^{2+} / \mathrm{Co}^{3+}$ transition and at $1.63 \mathrm{~V}$ versus $\mathrm{RHE}$ to the $\mathrm{Co}^{3+} / \mathrm{Co}^{4+}$ transition. The latter is not clearly resolved in our CV series (Figure 2). Similar peak posi- tions were reported by Villalobos et al., ${ }^{[43]}$ who also showed that the use of arsenate electrolyte for the electrodeposition of CoCat (instead of $\mathrm{KPi}$ ) resulted in a shift of $0.1 \mathrm{~V}$ in the peak position of the $\mathrm{Co}^{2+} / \mathrm{Co}^{3+}$ transition to lower potential, whereas the $\mathrm{Co}^{3+} / \mathrm{Co}^{4+}$ remained unaffected. Therefore, the position of the waves in the $\mathrm{CV}$ depends on the electrolyte used for restructuring, which means that the energy level of the Co redox can be tuned simply by the selection of the electrolyte anion similarly to the approach of Wang et al. ${ }^{[23]}$ who tune the cation of the catalyst material.

Three indicators were used to monitor the electrochemical restructuring during cycling in the three electrolytes with the most pronounced change, namely borate, phosphate, and carbonate. The indicators were I) estimation of the number of redox-active metal ions by the quantification of ERC, II) loss of the Ery phase from the initial material by X-ray diffraction (XRD) using the normalized (020) reflection of Ery (Figure S7, Supporting Information), and (III) anion exchange tracked as loss of arsenate from Ery $\left(\mathrm{Co}_{3}\left(\mathrm{AsO}_{4}\right)_{2} \cdot 8 \mathrm{H}_{2} \mathrm{O}\right)$ by energy-dispersive X-ray spectroscopy (EDX; Figure S8, Supporting Information). The arsenic content was normalized by the cobalt content to ensure that the changes are not due to material loss. The loss of arsenate anions was also tracked by the signal of the As-O bond ${ }^{[49]}$ at $780 \mathrm{~cm}^{-1}$ in Fourier transform infrared (FTIR) spectroscopy (Figure S9, Supporting Information), corroborating the EDX results. These tracking experiments were based on the methods and properties most commonly used to understand the electrochemical restructuring process. ${ }^{[10,12,15,43,50]}$ How the changes of metal redox, loss of crystallinity, and anionic exchange relate to each other has been an important open question for understanding the mechanism of electrochemical restructuring. In this regard, these three indicators were compared as a function of cycling in borate, carbonate, and phosphate electrolytes to identify trends and correlations (Figure 3). They were complemented by $j_{\max }$ as an indicator of activity as extracted from the CVs in Figure 2 and Figure S4 (Supporting Information).

In Ery- $\mathrm{BO}_{3}$ (Figure 3a), a plateau was reached by cycle 300 in all indicators, where the material has lost most of Ery's arsenate anions $(\mathrm{As} / \mathrm{Co} \approx 20 \%)$, the ERC reached a value of only $7 \mathrm{mC}$, and it did not show extended long-range order anymore, i.e., the normalized (020) reflection is $<1 \%$ of its initial value. Thus, 300 cycles in borate electrolyte were sufficient to conclude the electrochemical restructuring. Scanning electron microscopy (SEM) images taken at selected cycles showed a constant homogeneous coverage of the substrate for all cycles (Figure S10, Supporting Information). However, the initial needle-like morphology melted with cycling, which was most pronounced after 300 cycles (Figure S10e, Supporting Information). Interestingly, the activity measured by $j_{\max }$ reached its maximum at cycle 180 before the restructuring was completed and then started to decrease, indicating the additional relevance of further materials changes, such as the morphology, for catalytic activity. In summary, all restructuring indicators were correlated for Ery- $\mathrm{BO}_{3}$.

In Ery- $\mathrm{PO}_{4}$ (Figure 3b), the ERC trend differed from the other two indicators of the As/Co ratio and the reduction of the normalized Ery(020) reflection. These two indicators shared the same trend and mainly increase during the first 400 cycles. (Note that their axes are plotted with the lowest value on top to 


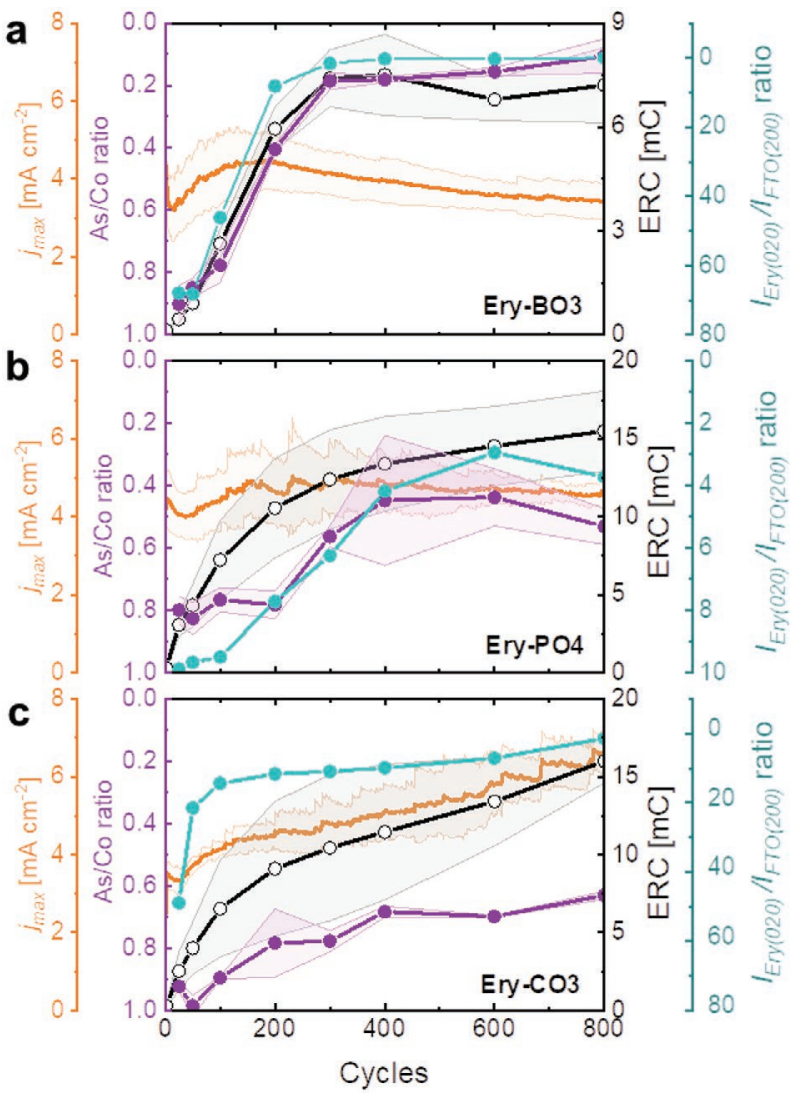

Figure 3. The three restructuring indicators As/Co ratio, $I_{\mathrm{Ery}(020)} / I_{\mathrm{FTO}(200)}$, and ERC as a function of cycling in a) borate $\left(E r y-\mathrm{BO}_{3}\right)$, b) phosphate $\left(\right.$ Ery- $\left.-\mathrm{PO}_{4}\right)$, and c) carbonate electrolyte $\left(\mathrm{Ery}-\mathrm{CO}_{3}\right)$. The light-colored area represents the standard deviation of three independent measurements. The As/Co ratio was obtained from EDX analysis (Figure S8, Supporting Information). The $j_{\max }$ was extracted from CV. The ERC was obtained by the area integration of the cathodic current in the CV. The $I_{\text {Ery (020) }} / I_{\text {FTO(200) }}$ ratio was obtained by integration of the Ery $(020)$ peak and its subsequent normalization by the integral of the FTO(200) peak. Dataset in ref. [48].

better compare them to the ERC) Less than $50 \%$ of the arsenate was lost in Ery- $\mathrm{PO}_{4}$, and the material still showed sizable longrange order after 800 cycles, meaning that the processes follow different kinetics in phosphate electrolytes as compared to borate electrolytes. Furthermore, the increase in redox activity (i.e., ERC) does not solely depend on restructuring the material. The ERC increased continuously over 800 cycles and reached a final value of $15.5 \mathrm{mC}$; an ERC increase has commonly been related to the generation of more active sites..$^{[8,12,13]}$ SEM images showed full coverage again at all cycles and a needle-like morphology but the images had no clear trend with cycling (Figure S11, Supporting Information). The activity indicator, $j_{\max }$, did not change remarkably over cycling, yet a broad maximum of the average $j_{\max }$ was found around cycle 300 , again before the restructuring was completed. In summary, for Ery- $\mathrm{PO}_{4}$, the partial loss of the Ery crystalline structure correlates with the loss of As during restructuring, whereas the ERC increased continuously and independently of the two other indicators.

In Ery- $\mathrm{CO}_{3}$, the ERC also continuously increased, whereas the As/Co ratio and the Ery crystallinity mainly decreased during the first 200 cycles and then remained nearly constant.
On this plateau, less than $50 \%$ of the arsenate was lost. After 200 cycles, the crystallinity drops significantly from $I_{\mathrm{Ery}(020)} / I_{\mathrm{FTO}(200)}=48.9$ to $I_{\mathrm{Ery}(020)} / I_{\mathrm{FTO}(200)}=11.7$ and decreases further until 800 cycles $\left(I_{\mathrm{Ery}(020)} / I_{\mathrm{FTO}(200)}=1.4\right.$, i.e., $3 \%$ of the initial value; Figure S7b, Supporting Information). In contrast, the ERC increased continuously with cycling and reached a value of $16 \mathrm{mC}$ (the highest among the three electrolytes). Interestingly, the activity indicator $j_{\max }$ decreased during the first 25 cycles, yet it increased continuously from cycle 25 up to cycle 800 , indicating an evident twofold increase of the current density during restructuring of Ery- $\mathrm{CO}_{3}$. In summary, none of the restructuring indicators correlated for Ery- $\mathrm{CO}_{3}$, yet the electrochemical current increased monotonously.

Taken together, the data in Figure 3 showed that the electrolyte anions affected the evolution of restructuring on Ery with cycling and clearly influenced how the different dynamic processes, e.g., loss of Ery crystallinity, anionic exchange, and increase of redoxactive Co (i.e., ERC), correlate with each other. Previous reports have shown the relation between the electrolyte $\mathrm{pH}^{[51]}$ or the cation stoichiometry ${ }^{[23]}$ with the efficiency of restructuring. Here, the lack of correlation between the ERC and the other restructuring indicators for some electrolytes suggests further change in the resulting local and electronic structures as additional factors.

We used X-ray absorption spectroscopy (XAS) to understand the changes in local structure during cycling in different electrolytes as it does not require crystallinity and has high chemical sensitivity. The Co- $K$ edge was used to analyze the Co oxidation state and local structure after a selected number of cycles. The nominal Co oxidation state was estimated by calibration with three Co references in different oxidation states (Figure S12 and Table S3, Supporting Information). The spectrum of the X-ray absorption near edge structure (XANES) of pristine Ery had a Co oxidation state of 2+ (Figure 4a). For Ery $-\mathrm{BO}_{3}$, the catalyst material showed a shift in the X-ray edge position to higher energy, indicating oxidation to $2.3+$ at 100 cycles and $2.8+$ at 800 cycles. Similar continuous oxidation was observed for Ery- $\mathrm{CO}_{3}$ from $2+$ to $2.4+$ at 100 cycles and $2.8+$ at 800 cycles. Moreover, for Ery- $\mathrm{CO}_{3}$ after 100 cycles, the Co edge looks different from Ery or layered $\mathrm{LiCoO}_{2}$, suggesting an intermediate structure between the initial and final restructured materials. The Co atoms of Ery $-\mathrm{PO}_{4}$ oxidized to $2.4+$ at cycle 100, which remained unchanged until cycle 800 . A doublet peak in the white line (i.e., their maximum) of the XANES spectra suggested a combination of two different phases, Ery and another Co oxide, ${ }^{[43]}$ to be identified below. It was observed in all spectra for Ery $-\mathrm{PO}_{4}$. In Ery- $\mathrm{BO}_{3}$, the doublet peak in the white line was observed only in cycle 100 but not in cycle 800 , indicating a single-phase material in agreement with the vanished Ery (020) reflection in XRD. In Ery- $\mathrm{CO}_{3}$, the other Co oxide contributed negligibly at cycle 100 , and the doublet peak in the white line was observed only after 800 cycles, also in agreement with partial loss of the Ery structure in XRD.

The FT of the EXAFS at the Co-K edge was used to study the local structure of the electrochemically restructured Ery after a selected number of cycles in borate, electrolyte, and carbonate electrolytes (Figure 4b). The FT of pristine Ery has a prominent peak at $2.1 \AA(\mathrm{Co}-\mathrm{O})$ and a weaker one at $3.1 \AA(\mathrm{Co}-\mathrm{Co}) .{ }^{[43]}$

The spectrum of Ery- $\mathrm{PO}_{4}$ showed EXAFS peaks similar to pristine Ery after 100 and 800 cycles having the above $\mathrm{Co}-\mathrm{O}$ 

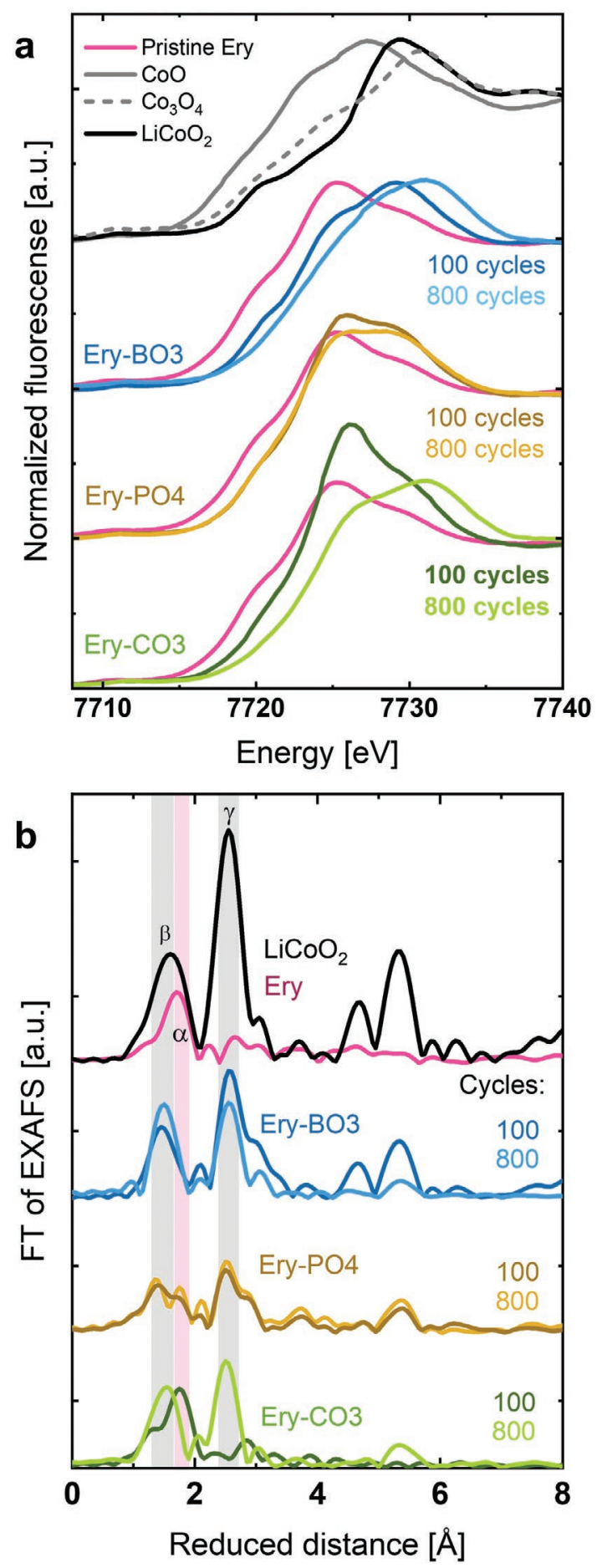

Figure 4. a) XANES spectra of Co-K edge collected on Ery after selected cycles in $0.1 \mathrm{M}$ electrolytes of borate, phosphate, and carbonate at $\mathrm{pH}$ 7. The Co- $\mathrm{K}$ edge spectra of $\mathrm{Co}^{(2+)} \mathrm{O}, \mathrm{CO}_{3}{ }^{(2.7+)} \mathrm{O}_{4}$, and $\mathrm{LiCo}^{(3+)} \mathrm{O}_{2}$ were added as references, b) Fourier transform of the EXAFS of the Co- $K$ edge collected on Ery after selected cycles in $0.1 \mathrm{M}$ electrolytes of borate, phosphate, and carbonate at $\mathrm{pH}$ 7. The light-colored gray areas highlight the interatomic distances related to layered Co oxides (peaks $\beta$ and $\gamma$, whereas the light-colored pink areas show the distance of $2.1 \AA$ typical for Ery ( $\mathrm{Co}-\mathrm{O}$, peak $\alpha)$. The reduced distance is about $0.3 \AA$ shorter than the precise distance obtained by EXAFS simulations (Figures S13-S15 and Table S4, Supporting Information). The spectra in all panels were offset on the $y$-axis to group them. Dataset in ref. [48]. and $\mathrm{Co}-\mathrm{Co}$ distances typical of Ery. ${ }^{[3]}$ Additionally, distances at $1.9 \AA(\mathrm{Co}-\mathrm{O})$ and $2.85 \AA(\mathrm{Co}-\mathrm{Co})$ were visible; these are distinct signals of layered Co oxides such as $\mathrm{LiCoO}_{2}$ that is also shown in Figure 4b for reference. The lack of change in the spectra was expected based on the XANES analysis above. The presence of Ery and a layered Co oxide corroborates our interpretation of the doublet peak in the white line.

The spectrum of Ery- $\mathrm{BO}_{3}$ after 100 cycles also showed the peaks of Ery and the layered Co oxide. After cycle 800, the spectrum only showed the prominent peaks of a Co oxide, such as $1.9 \AA(\mathrm{Co}-\mathrm{O})$ and $2.8 \AA(\mathrm{Co}-\mathrm{Co})$, indicating complete electrochemical restructuring. Interestingly, the distance at $3.7 \AA$ (Co-O, Figure 1) significantly decreases its amplitude. This signal has been previously associated with the distance between Co atoms into the oxide layer and oxygen atoms, either from water molecules or electrolyte ions, in the interlayer. ${ }^{[8,37,38]} \mathrm{A}$ reduction of this signal amplitude may reflect a decrease in the long-range order of the layered Co oxide.

In Ery- $\mathrm{CO}_{3}$, the nearly complete electrochemical restructuring from Ery into a layered Co oxide was apparent. After 100 cycles, the interatomic distance at $2.1 \AA(\mathrm{Co}-\mathrm{O})$ evidenced the presence of Ery; no distances associated with layered Co oxides were observed. Nonetheless, after cycle 800 , the spectrum showed the interatomic distances at $1.9 \AA(\mathrm{Co}-\mathrm{O})$ and $2.85 \AA$ (Co-Co) of the Co oxide, and signals of the Ery structure were not clearly observed, which do not exclude minor contributions from the Ery structure as found by XRD and suggested by the XANES.

Since the layered Co oxide formed to various degrees in all electrolytes, we will take a closer look at its properties to rationalize the differences in activity among the restructured Ery catalysts. Amorphous Co oxides are organized in layers of several hexa-oxo-coordinated Co atoms; the number of Co atoms determines the extent of the layer fragment or cluster. ${ }^{[3,39,52]}$ The cluster size of amorphous Co oxide has been used previously to understand activity trends on electrodeposited and restructured Co oxides. ${ }^{[8,36,38]}$ The cluster size of the Co oxide is effectively monitored by the ratio of the $\mathrm{Co}-\mathrm{Co}$ peak height to the $\mathrm{Co}-\mathrm{O}$ peak height (cobalt peak ratio, CPR) in the FT of EXAFS. A large CPR indicates a large cluster or ultimately a crystalline solid such as $\mathrm{LiCoO}_{2}$ in Figure 4b, but its exact value depends on the $k$-weighting applied to the EXAFS data and parameters of the FT, which were identical for our analysis. Using highly crystalline $\mathrm{LiCoO}_{2}$ as a reference, the upper limit of the CPR in our analysis is estimated as 2.1. In the limit of an isolated octahedron, the CPR would be zero.

We plotted the activity indicator, $j_{\max }$, as a function of the CPR (Figure 5a) to further investigate the nature of the layered Co oxide formed by restructuring Ery. For each individual dataset, $j_{\max }$ increased with the CPR. This explained the activity decrease with cycling for Ery $-\mathrm{PO}_{4}$ and Ery- $\mathrm{BO}_{3}$ where CPR and activity were maximal after 400 and 100 cycles. However, the exact value of the CPR does not result in the same activity for electrochemical restructuring in different electrolytes, which suggested that another parameter also strongly affected activity.

The role of a high Co oxidation state (3+ and even 4+) has been widely reported as essential for oxygen evolution in neutral electrolytes..$^{[13,31,53-57]}$ Thus, we plotted the restructured Ery catalysts as a function of the average Co oxidation state 

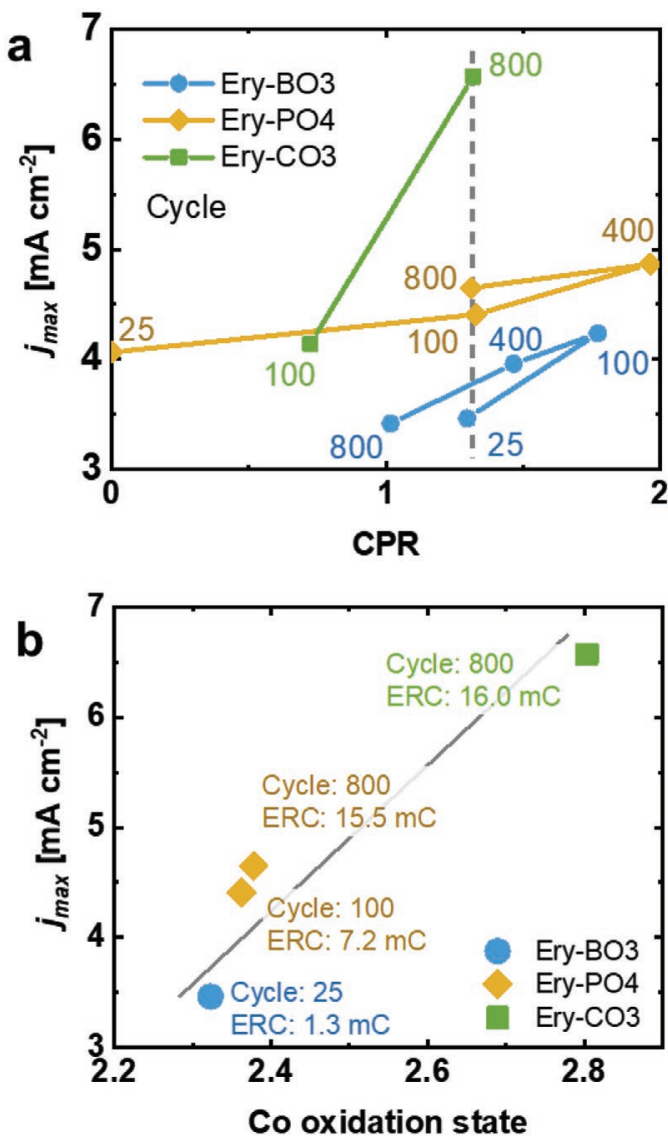

Figure 5. a) The activity indicator, $j_{\max }$, as a function of the CPR obtained from the Fourier transform of the EXAFS of Ery in borate, phosphate, and carbonate after a selected number of cycles (shown in the graph). The solid lines connect the dots in chronological order (based on cycling). b) The activity indicator $j_{\max }$ (at $2.1 \mathrm{~V}$ vs RHE) as a function of the average Co oxidation state of Ery in borate (25 cycles), phosphate (100 and 800 cycles), and carbonate ( 800 cycles) at a CPR of 1.3. Dataset in ref. [48].

(Figure 5b) at a fixed CPR of 1.3. The plot was further enriched with the ERC at each point to discuss the number of potentially active sites provided by the ERC as well as the efficiency of a single active site, likely given by its Co oxidation state.

In Figure 5b, after 100 cycles in phosphate, the Co oxidation of Ery- $\mathrm{PO}_{4}$ is also $2.4+$, yet the ERC is only $7.2 \mathrm{mC}$, resulting in a lower catalytic current density $\left(4.4 \mathrm{~mA} \mathrm{~cm}^{-2}\right)$ due to comparably fewer (redox) active sites as compared to Ery $-\mathrm{PO}_{4}$ after 800 cycles. After 25 cycles in borate, the ERC $(1.3 \mathrm{mC})$ and Co oxidation state (2.3+) of Ery- $\mathrm{BO}_{3}$ are the lowest among the samples, associated with the lowest current density $\left(3.5 \mathrm{~mA} \mathrm{~cm}^{-2}\right)$. In particular, the comparison of Ery- $-\mathrm{PO}_{4}$ at different cycles and fixed CPR clearly highlighted the importance of the number of redox active sites for high current.

For Ery $-\mathrm{CO}_{3}$, Co atoms have the highest oxidation state $(2.8+)$, the highest ERC $(16.0 \mathrm{mC})$, which results in the highest current density $\left(6.6 \mathrm{~mA} \mathrm{~cm}{ }^{-2}\right)$. After 800 cycles on Ery- $\mathrm{PO}_{4}$, the ERC is almost as high as that of Ery- $\mathrm{CO}_{3}(15.5 \mathrm{mC})$, yet the oxidation state is only $2.4+$, resulting in a significantly lower catalytic current density $\left(4.6 \mathrm{~mA} \mathrm{~cm}{ }^{-2}\right)$. Even though the redox activity is very similar and the Co oxide clusters have an appro- priate size (a CPR of 1.3), a high Co oxidation state is required additionally to increase the catalytic current. ${ }^{[55,56,58]}$ Therefore, we conclude that the more oxidized active sites in Ery- $-\mathrm{CO}_{3}$ are more efficient as compared to Ery- $\mathrm{PO}_{4}$.

The efficiency of the active sites was quantified by the normalization of $j_{\max }$ by ERC, which corresponds to four times the TOF of $\mathrm{O}_{2}$ per Co active site due to the four electrons transferred in the reaction Figure 6. ${ }^{[8,12,13]}$ Note that ERC was used in the calculation (full detail in Table S5 in the Supporting Information), which is an estimation of the number Co atoms with oxidation state changes; therefore, it also counts subsurface Co atoms that were oxidized and not involved in the catalytic reaction. Thus, the TOF is underestimated. The initial TOF of Ery was clearly higher than that of the restructured catalysts, as discussed in detail for a related structure, ${ }^{[12]}$ suggesting that crystallinity benefits the efficiency of an active site. For Ery- $\mathrm{PO}_{4}$, the TOF decreased continuously, whereas it reached a steady value after 200-300 cycles for Ery- $\mathrm{BO}_{3}$ and Ery- $\mathrm{CO}_{3}$. The TOF of Ery- $\mathrm{CO}_{3}$ after 800 cycles $\left(1.3 \times 10^{-2} \mathrm{O}_{2} \mathrm{Co}^{-1} \mathrm{~s}^{-1}\right.$ at $0.3 \mathrm{~V}$ overpotential; Figure S16 and Table S1, Supporting Information) was slightly higher than that of other Co oxides at the same overpotential, even those measured in alkaline media, where the activity is usually higher. ${ }^{[59,60]}$ Moreover, its TOF was in the range of amorphous electrodeposited Co oxide, ${ }^{[61]}$ supporting that a similar surface is produced by restructuring Ery and electrodepositing Co oxide. Tafel slopes of Ery- $\mathrm{CO}_{3}$ were evaluated before and after activation in carbonate electrolyte (Figure S17, Supporting Information) to examine if the current changes were due to different mechanisms. ${ }^{[62]}$ Yet, the Tafel slopes remain unaffected after activation, suggesting an unchanged mechanism. However, the Tafel slope values of Ery- $\mathrm{CO}_{3}$ were higher $\left(145 \mathrm{mV}\right.$ decade $\left.{ }^{-1}\right)$ as compared to Ery- $\mathrm{PO}_{4}$ (72 $\mathrm{mV}$ decade $^{-1}$ ), which were evaluated under the same conditions previously, ${ }^{[43]}$ indicating an electrolyte-dependent mechanism. Therefore, the increase of $j_{\max }$ for Ery- $\mathrm{CO}_{3}$ was most likely due to an increase in the number of active sites in the restructured catalyst with cycling rather than an increase in the efficiency of the active sites (Figure 6).

\section{Summary and Conclusion}

Ery was used to identify the requirements for catalyst activation by electrochemical restructuring, for which we defined the indicators of the redox active Co (ERC), loss of Ery crystal structure, and anion exchange. All investigated electrolytes led to electrochemical restructuring to an amorphous layered cobalt (hydr)oxide to various degrees as demonstrated by XRD and EXAFS analyses. In Ery- $\mathrm{BO}_{3}$, all three restructuring indicators correlated with cycling. In Ery- $\mathrm{PO}_{4}$, only two indicators correlated: the loss of the Ery structure and arsenate, while the ERC increased monotonously. In the most interesting case of Ery- $\mathrm{CO}_{3}$, none of the indicators correlated over 800 cycles. This indicated that the evolution of the restructuring processes with cycling, both structural and compositional, differed strongly in the selected electrolytes. Furthermore, the ERC increased by a factor of around 55 for Ery $-\mathrm{BO}_{3}$, Ery $-\mathrm{PO}_{4}$, and Ery $-\mathrm{CO}_{3}$, which suggests an equal increase in the number of active sites on these restructured 

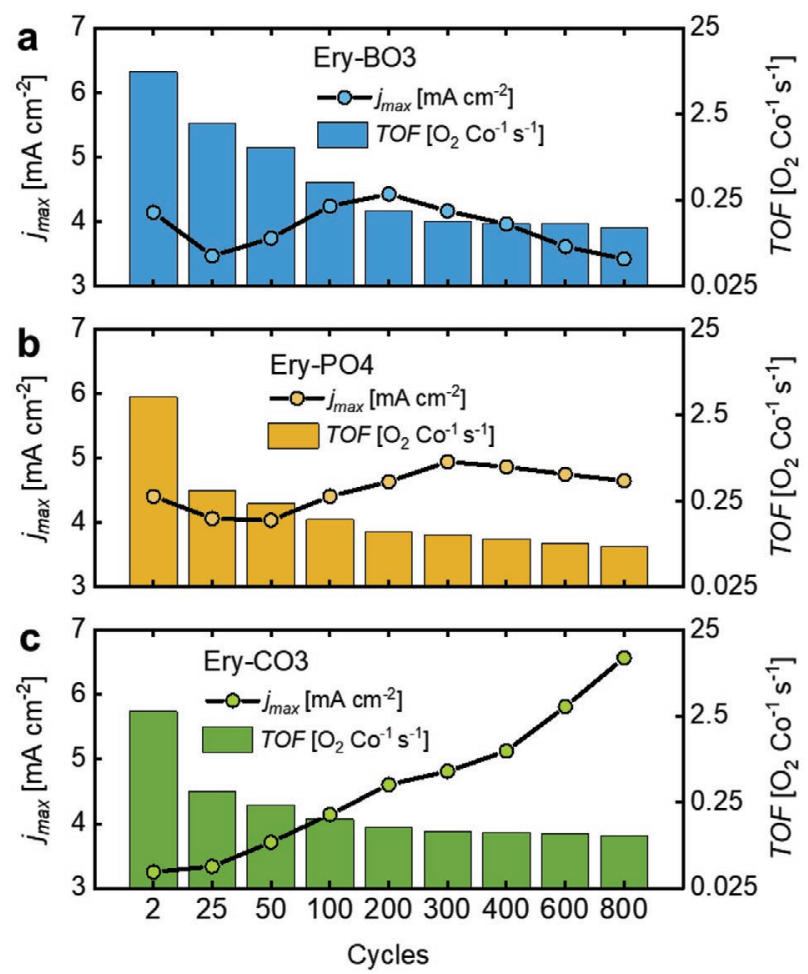

Figure 6. Relationship between the current density, $j_{\max }$, (left $y$-axis, symbols) and TOF per redox-active site (right $y$-axis, bars) as a function of cycling in a) borate electrolyte, b) phosphate electrolyte, and c) carbonate electrolyte. $j_{\max }$ was evaluated at $2.1 \mathrm{~V}$ versus RHE. The TOF was estimated by the normalization of $j_{\max }$ by ERC and the four transferred electrons. Dataset in ref. [48].

materials. Yet, its continuous increase resulted in the desired increase in activity only for Ery- $\mathrm{CO}_{3}$. This highlights that the restructuring and activation are two separate processes, where activation has further requirements.

For activation, a large cluster size (i.e., high CPR) and high Co valence of the restructured surface (hydr)oxide were beneficial. An adequate cluster size has been reported to play an essential role in the mesostructure arrangement, which, together with intercalated electrolyte anions, impacts the electrical conductivity properties of the material. ${ }^{[27,29]}$ We hypothesize that a larger cluster size also aids in keeping anions in the amorphous structure where they act a proton buffers, ${ }^{[13,63]}$ so that larger clusters can support higher currents. Finally, we found that the current increased with the Co oxidation state at a fixed cluster size where an average oxidation state of 2.8 produced the highest activity. This is a typical oxidation state of a layered double hydroxide ${ }^{[31,61,64]}$ and close to ex situ measurements of electrodeposited Co oxide. ${ }^{[37,38]}$

In summary, our work highlights the role of the electrolyte for electrochemical restructuring, where we found surprisingly different behavior of the restructured Ery. We expect that the simple method of anion exchange can be utilized in a wide range of catalyst materials, e.g., (oxy)phosphates, ${ }^{[12,13]}$ fluorides, ${ }^{[65]}$ oxychlorides, ${ }^{[23]}$ multimetallic oxyhydroxides, ${ }^{[18,24,66,67]}$ and perovskites, ${ }^{[36]}$ to control catalyst activation by restructuring with an optimal trinity of local order, transition metal valence, and high number of active sites.

\section{Experimental Section}

Materials: $\mathrm{CoSO}_{4} \cdot 7 \mathrm{H}_{2} \mathrm{O}$ (Merck, 99,5\%), $\mathrm{Na}_{2} \mathrm{HAsO}_{4} \cdot 7 \mathrm{H}_{2} \mathrm{O}$ (Merck, 99,5\%), Nafion $1175 \%$ in ethanol (Sigma-Aldrich), FTO Pilkinton NSC TEC T15, $\mathrm{K}_{2} \mathrm{HPO}_{4}$ (Riedel-De Haën, 98\%), $\mathrm{KH}_{2} \mathrm{PO}_{4}$ (Merck, >99,5\%), $\mathrm{H}_{3} \mathrm{BO}_{3}$ (Sigma-Aldrich >99,5\%), $\mathrm{HCl}$ (Merk, 32\%), $\mathrm{NaHCO}_{3}$ (Merk, 99,5\%), isopropanol (Labquimar, 99,9\%), MiliQ water $(>18 \mathrm{M} \Omega \mathrm{cm}$ ), and $\mathrm{CaCl}_{2}$ (Merk, PA).

Synthesis of Ery: About $400 \mathrm{~mL}$ of $7 \times 10^{-3} \mathrm{M} \mathrm{Na}_{2} \mathrm{HAsO}_{4} \cdot 7 \mathrm{H}_{2} \mathrm{O}$ solution was added dropwise to $800 \mathrm{~mL}$ of $5 \times 10^{-3} \mathrm{M} \mathrm{CoSO}_{4}$ solution at $65{ }^{\circ} \mathrm{C}$. The reddish solution of Co turned pink after several drops, and a precipitate started forming. The final suspension was stirred and heated (at $65^{\circ} \mathrm{C}$ ) for $72 \mathrm{~h}$. The obtained solid was washed five times with deionized water and dried at room temperature and vacuum using $\mathrm{CaCl}_{2}$ as a desiccant. The resulting product was denoted as "Ery" herein.

Electrode Preparation: About $5.00 \mathrm{mg}$ of Ery was added to $1000 \mu \mathrm{L}$ of isopropanol, and then the suspension was sonicated for $2 \mathrm{~h}$ to get a higher dispersion. About $80 \mu \mathrm{L}$ of this suspension was slowly dropcoated on a $1 \mathrm{~cm} \times 1 \mathrm{~cm}$ FTO glass surface. Once the isopropanol evaporated, $15 \mu \mathrm{L}$ of $0.25 \%$ Nafion was drop-coated three times on the electrode's surface, waiting for 5 min between each addition.

Electrolyte Preparation: All electrolytes were prepared at $\mathrm{pH} 7$ (measured with a Daigger $5500 \mathrm{pH}$ Meter) and $0.1 \mathrm{M}$ concentration. For phosphate electrolyte, $0.1 \mathrm{M} \mathrm{K}_{2} \mathrm{HPO}_{4}$ and $0.1 \mathrm{M} \mathrm{KH}_{2} \mathrm{PO}_{4}$ solutions were prepared and mixed in an adequate ratio to adjust to $\mathrm{pH}$ 7. For borate electrolyte, $0.1 \mathrm{M} \mathrm{B}_{4} \mathrm{Na}_{2} \mathrm{O}_{7}$ solution was prepared, and $0.1 \mathrm{M}$ $\mathrm{HCl}$ solution was added dropwise to adjust to $\mathrm{pH}$ 7. For carbonate electrolyte, $0.1 \mathrm{M} \mathrm{NaHCO}_{3}$ solution was prepared, and $0.1 \mathrm{M} \mathrm{HCl}$ solution was added dropwise to adjust to $\mathrm{pH}$ 7. For arsenate electrolyte, $0.1 \mathrm{M} \mathrm{Na}_{2} \mathrm{HAsO}_{4} \cdot 7 \mathrm{H}_{2} \mathrm{O}$ solution was prepared, and $0.1 \mathrm{M} \mathrm{HCl}$ solution was added dropwise to adjust to $\mathrm{pH} 7$.

Electrochemical Measurements: The experiments were carried out on FTO glass electrodes as the working electrode in a single-compartment three-electrode electrochemical cell made of glass and filled with about $50 \mathrm{~mL}$ solution of the electrolyte. A high surface Pt mesh counter electrode and an $\mathrm{Ag} / \mathrm{AgCl}(\mathrm{KCl}$ saturated) reference electrode (separation of about $1 \mathrm{~cm}$ ) were used. The electrochemical experiments were performed at room temperature using a potentiostat (SP-300, BioLogic Science Instruments) controlled by the EC-Lab v11.01 software package. The typical electrolyte resistance (including the electrode) was about $65 \Omega ; i R$ compensation at $85 \%$ was dynamically applied. The solution remained unstirred during the experiments. All potentials were calculated and converted with respect to the RHE.

$X$-Ray Diffraction: Diffractograms were collected using a Bruker D8 Göbel-Mirror for grazing incidence in PT006 and an energy-dispersive Sol-X detector. Cu-Anode $(K \alpha]+2)$ was used as source of $\mathrm{X}$-ray. Data were collected in the range of $2 \theta=10^{\circ}-70^{\circ}$ with increments of $0.02^{\circ}$ and an equivalent time of $10 \mathrm{~s}$ per step. The measurements were carried out at the X-ray Core Lab at Helmholtz-Zentrum Berlin (HZB). The (020) reflection of Ery $\left(2 \theta=13^{\circ}\right)$ normalized by the (200) reflection of FTO $\left(2 \theta=38^{\circ}\right)$ was used as an indicator of the crystalline Ery phase.

Scanning Electron Microscopy and Energy-Dispersive X-Ray Spectroscopy: Sample morphology was determined using a low vacuum scanning electron microscope, Hitachi S-3700N, with an acceleration voltage of $10 \mathrm{keV}$ and detecting secondary electrons. EDX measurements were performed using an energy-dispersive X-ray analysis probe, Oxford, and a Hitachi S-570 with an Aspe model Sirius 10/7.5 EDS. Normalization by the amount of Co guarantees that changes in As are due not to the dissolution of the material itself.

$X$-Ray Absorption Spectroscopy: Hard XAS spectra at Co-K edge were collected at the KMC-3 beamline ${ }^{[68]}$ at Helmholtz-Zentrum Berlin. Spectra were recorded in fluorescence mode using a 13 element silicon drift detector (SDD) from RaySpec. The used monochromator was a double-crystal Si (111), and the polarization of the beam was horizontal. Reference samples were prepared by dispersing a thin and homogeneous layer of the ground powder on Kapton tape. After removing the excess material, the tape was sealed, and the excess of Kapton was folded several times to get $1 \mathrm{~cm} \times 1 \mathrm{~cm}$ windows. The energy 
was calibrated using a Co metal foil (fitted reference energy of $7709 \mathrm{eV}$ in the first derivative spectrum) with an accuracy $\pm 0.1 \mathrm{eV}$. Up to three scans of each sample were collected to $k=14 \AA^{-1}$.

All spectra were normalized by subtracting a straight line obtained by fitting the data before the $K$ edge and division by a polynomial function obtained by fitting the data after the $K$ edge, as illustrated elsewhere. ${ }^{[14]}$ The FT of the EXAFS was calculated between 15 and $800 \mathrm{eV}$ above the Co- $K$ edge $\left(E_{0}=7709 \mathrm{eV}\right)$. A cosine window covering $10 \%$ on the left side and $10 \%$ on the right side of the EXAFS spectra was used to suppress the side lobes in the FTs. Weighing of the intensity by $k^{3}$ was chosen to emphasize the heavier scatterers, i.e., Co, and thereby which samples had extended local order and which lacked it.

EXAFS simulations were performed using the software SimXLite. After calculating the phase functions with the FEFF8-Lite ${ }^{[69]}$ program (version 8.5.3, self-consistent field option activated), atomic coordinates of the FEFF input files were generated from the structure of Ery and other several reasonable structural models (Figure S1, Supporting Information); the EXAFS phase functions did not depend strongly on the details of the used model. An amplitude reduction factor $\left(S_{0}^{2}\right)$ of 0.85 was used, which is typical for Co oxides. ${ }^{[43]}$ The data range used in the simulation was $34-747 \mathrm{eV}\left(3.0-14.0 \AA^{-1}\right)$ above the Co- $K$ edge $\left(E_{0}=\right.$ $7709 \mathrm{eV}$ ). The EXAFS simulations were optimized by minimizing the error sum obtained by summation of the squared deviations between measured and simulated values (least-squares fit). The fit was performed using the Levenberg-Marquardt method with numerical derivatives.

\section{Supporting Information}

Supporting Information is available from the Wiley Online Library or from the author.

\section{Acknowledgements}

The authors thank Dr. Dulce Morales, Denis Antipin, and Joaquin Morales for helping in XAS data collection, and David Sánchez and Gabriela Fernández for helping in electrochemical measurements. The authors acknowledge Dr. Michael Haumann and Dr. Ivo Zizak for the support at the beamline; Dr. Katharina Klingan and Prof. Holger Dau for fruitful discussion; and Dr. Petko Chernev for permission to use his software SimXLite. The authors also thank Helmholtz-Zentrum Berlin (HZB) for the allocation of synchrotron radiation beamtime at BESSY, KMC-3. The XAS experiments were financially supported by funds allocated to Prof. Holger Dau (Freie Univ. Berlin) by the Bundesministerium für Bildung und Forschung (BMBF, 05K19KE1, OPERANDO-XAS) and by the Deutsche Forschungsgemeinschaft (DFG, German Research Foundation) under Germany's Excellence StrategyEXC 2008-390540038-UniSysCat. The authors again thank HZB X-ray CoreLab for training and advising in XRD. This project received funding from Posgrado en Química and Vicerrectoría de Investigación (UCR), CONICIT-MICIT (Costa Rica), and the European Research Council (ERC) under the European Union's Horizon 2020 Research and Innovation Programme under grant agreement No. 804092.

Open access funding enabled and organized by Projekt DEAL.

\section{Conflict of Interest}

The authors declare no conflict of interest.

\section{Data Availability Statement}

The data that support the findings of this study are openly available in Figshare at http://doi.org/10.6084/m9.figshare.14717997.

\section{Keywords}

catalyst activation, Co-based electrocatalysts, electrochemical reconstruction, electrolyte, oxygen evolution reaction

Received: June 4, 2027

Revised: July 15, 2021

Published online: August 7, 2021

[1] D. G. Nocera, Acc. Chem. Res. 2017, 50, 616.

[2] M. Risch, Nat. Energy 2021, 6, 576.

[3] S. Chu, A. Majumdar, Nature 2012, 488, 294.

[4] C. W. Li, J. Ciston, M. W. Kanan, Nature 2014, 508, 504.

[5] C. Liu, B. C. Colón, M. Ziesack, P. A. Silver, D. G. Nocera, Science 2016, 352, 602.

[6] R. D. L. Smith, C. Pasquini, S. Loos, P. Chernev, K. Klingan, P. Kubella, M. R. Mohammadi, D. Gonzalez-Flores, H. Dau, Nat. Commun. 2017, 8, 2022.

[7] J. Liu, Y. Ji, J. Nai, X. Niu, Y. Luo, L. Guo, S. Yang, Energy Environ. Sci. 2018, 11, 1736.

[8] M. Risch, K. Klingan, F. Ringleb, P. Chernev, I. Zaharieva, A. Fischer, H. Dau, ChemSusChem 2012, 5, 542.

[9] W. Cai, R. Chen, H. Yang, H. B. Tao, H. Y. Wang, J. Gao, W. Liu, S. Liu, S. F. Hung, B. Liu, Nano Lett. 2020, 20, 4278.

[10] A. Indra, P. W. Menezes, N. R. Sahraie, A. Bergmann, C. Das, M. Tallarida, D. Schmeißer, P. Strasser, M. Driess, J. Am. Chem. Soc. 2014, 136, 17530.

[11] J. Li, C. A. Triana, W. Wan, D. P. Adiyeri Saseendran, Y. Zhao, S. E. Balaghi, S. Heidari, G. R. Patzke, Chem. Soc. Rev. 2021, 50, 2444.

[12] D. González-Flores, I. Sánchez, I. Zaharieva, K. Klingan, J. Heidkamp, P. Chernev, P. W. Menezes, M. Driess, H. Dau, M. L. Montero, Angew. Chem., Int. Ed. 2015, 54, 2472.

[13] K. Klingan, F. Ringleb, I. Zaharieva, J. Heidkamp, P. Chernev, D. Gonzalez-Flores, M. Risch, A. Fischer, H. Dau, ChemSusChem 2014, 7, 1301.

[14] J. Villalobos, R. Golnak, L. Xi, G. Schuck, M. Risch, JPhys Energy 2020, 2, 034009.

[15] A. Bergmann, E. Martinez-Moreno, D. Teschner, P. Chernev, M. Gliech, J. F. De Araújo, T. Reier, H. Dau, P. Strasser, Nat. Commun. 2015, 6, 8625.

[16] Y. Shi, Y. Yu, Y. Liang, Y. Du, B. Zhang, Angew. Chem., Int. Ed. 2019, $58,3769$.

[17] H. Jiang, Q. He, X. Li, X. Su, Y. Zhang, S. Chen, S. Zhang, G. Zhang, J. Jiang, Y. Luo, P. M. Ajayan, L. Song, Adv. Mater. 2019, 31, 1805127.

[18] A. Sivanantham, P. Ganesan, A. Vinu, S. Shanmugam, ACS Catal. 2020, 10, 463.

[19] E. Fabbri, M. Nachtegaal, T. Binninger, X. Cheng, B. J. Kim, J. Durst, F. Bozza, T. Graule, R. Schäublin, L. Wiles, M. Pertoso, N. Danilovic, K. E. Ayers, T. J. Schmidt, Nat. Mater. 2017, 16, 925.

[20] E. Tsuji, A. Imanishi, K. I. Fukui, Y. Nakato, Electrochim. Acta 2011, 56, 2009.

[21] X. Zhao, X. Chen, Y. Wang, P. Song, Y. Zhang, Sustainable Energy Fuels 2020, 4, 4733.

[22] X. Bao, Y. Li, J. Wang, Q. Zhong, ChemCatChem 2020, 12, 6259.

[23] J. Wang, S. J. Kim, J. Liu, Y. Gao, S. Choi, J. Han, H. Shin, S. Jo, J. Kim, F. Ciucci, H. Kim, Q. Li, W. Yang, X. Long, S. Yang, S. P. Cho, K. H. Chae, M. G. Kim, H. Kim, J. Lim, Nat. Catal. 2021, 4, 212.

[24] H. Jiang, Q. He, Y. Zhang, L. Song, Acc. Chem. Res. 2018, 51, 2968.

[25] C. Costentin, D. G. Nocera, Proc. Natl. Acad. Sci. USA 2017, 114, 13380.

[26] D. A. Lutterman, Y. Surendranath, D. G. Nocera, J. Am. Chem. Soc. 2009, 131, 3838. 
[27] C. Costentin, T. R. Porter, J. M. Savéant, J. Am. Chem. Soc. 2016, $138,5615$.

[28] G. Kwon, H. Jang, J. S. Lee, A. Mane, D. J. Mandia, S. R. Soltau, L. M. Utschig, A. B. F. Martinson, D. M. Tiede, H. Kim, J. Kim, J. Am. Chem. Soc. 2018, 140, 10710.

[29] C. Costentin, T. R. Porter, J. M. Savéant, ACS Appl. Mater. Interfaces 2019, 11, 28769.

[30] P. W. Menezes, A. Indra, N. R. Sahraie, A. Bergmann, P. Strasser, M. Driess, ChemSusChem 2015, 8, 164.

[31] M. Risch, F. Ringleb, M. Kohlhoff, P. Bogdanoff, P. Chernev, I. Zaharieva, H. Dau, Energy Environ. Sci. 2015, 8, 661.

[32] H. S. Ahn, T. D. Tilley, Adv. Funct. Mater. 2013, 23, 227.

[33] Y. Surendranath, M. W. Kanan, D. G. Nocera, J. Am. Chem. Soc. 2010, 132, 16501

[34] L. Ma, S. F. Hung, L. Zhang, W. Cai, H. Bin Yang, H. M. Chen, B. Liu, Ind. Eng. Chem. Res. 2018, 57, 1441.

[35] R. D. L. Smith, M. S. Prévot, R. D. Fagan, S. Trudel, C. P. Berlinguette, J. Am. Chem. Soc. 2013, 135, 11580.

[36] M. Risch, A. Grimaud, K. J. May, K. A. Stoerzinger, T. J. Chen, A. N. Mansour, Y. Shao-Horn, J. Phys. Chem. C 2013, 117, 8628.

[37] M. Risch, V. Khare, I. Zaharleva, L. Gerencser, P. Chernev, H. Dau, J. Am. Chem. Soc. 2009, 131, 6936.

[38] M. W. Kanan, J. Yano, Y. Surendranath, M. Dincă, V. K. Yachandra, D. G. Nocera, J. Am. Chem. Soc. 2010, 132, 13692.

[39] G. Kwon, O. Kokhan, A. Han, K. W. Chapman, P. J. Chupas, P. Du, D. M. Tiede, Acta Crystallogr., Sect. B: Struct. Sci., Cryst. Eng. Mater. 2015, 71, 713

[40] H. Mori, T. Ito, Acta Crystallogr. 1950, 3, 1.

[41] M. Wildner, G. Giester, C. L. Lengauer, C. A. Mccammon, Eur. J. Mineral. 1996, 8, 187.

[42] R. L. Frost, J. T. Kloprogge, W. N. Martens, J. Raman Spectrosc. 2004, $35,28$.

[43] J. Villalobos, D. González-Flores, K. Klingan, P. Chernev, P. Kubella, R. Urcuyo, C. Pasquini, M. R. Mohammadi, R. D. L. Smith, M. L. Montero, H. Dau, Phys. Chem. Chem. Phys. 2019, 21, 12485.

[44] X. Guo, F. Wu, G. Hao, S. Peng, N. Wang, Q. Li, Y. Hu, W. Jiang, Dalton Trans. 2019, 48, 5214

[45] X. Wang, R. Tong, Y. Wang, H. Tao, Z. Zhang, H. Wang, ACS Appl. Mater. Interfaces 2016, 8, 34270.

[46] T. Jiang, S. A. Ansar, X. Yan, C. Chen, X. Fan, F. Razmjooei, R. Reisser, G. Montavon, H. Liao, ACS Appl. Energy Mater. 2019, 2, 8809.

[47] F. Song, X. Hu, J. Am. Chem. Soc. 2014, 136, 16481.

[48] J. Villalobos, D. Gonzalez-Flores, R. Urcuyo, M. L. Montero, G. Schuck, P. Beyer, M. Risch, 2021, https://doi.org/10.6084/ m9.figshare.14717997.
[49] Y. Furutani, H. Kandori, Biochim. Biophys. Acta, Bioenerg. 2014, 1837, 598.

[50] P. Baláz, M. Baláz, O. Shpotyuk, P. Demchenko, M. Vlček, M. Shopska, J. Briančin, Z. Bujňakova, Y. Shpotyuk, B. Selepová, L. Balážova, J. Mater. Sci. 2017, 52, 1747.

[51] S. W. Lee, C. Carlton, M. Risch, Y. Surendranath, S. Chen, S. Furutsuki, A. Yamada, D. G. Nocera, Y. Shao-Horn, J. Am. Chem. Soc. 2012, 134, 16959.

[52] M. W. Kanan, D. G. Nocera, Science 2008, 321, 1072.

[53] D. K. Bediako, Y. Surendranath, D. G. Nocera, J. Am. Chem. Soc. 2013, 135, 3662.

[54] A. Grimaud, K. J. May, C. E. Carlton, Y. L. Lee, M. Risch, W. T. Hong, J. Zhou, Y. Shao-Horn, Nat. Commun. 2013, 4, 2439.

[55] J. Suntivich, K. J. May, H. A. Gasteiger, J. B. Goodenough, Y. Shao-horn, F. Calle-vallejo, A. D. Oscar, M. J. Kolb, M. T. M. Koper, J. Suntivich, K. J. May, H. A. Gasteiger, J. B. Goodenough, Y. Shao-horn, Science 2011, 334, 2010.

[56] D. Friebel, M. Bajdich, B. S. Yeo, M. W. Louie, D. J. Miller, H. Sanchez Casalongue, F. Mbuga, T. C. Weng, D. Nordlund, D. Sokaras, R. Alonso-Mori, A. T. Bell, A. Nilsson, Phys. Chem. Chem. Phys. 2013, 15, 17460.

[57] C. E. Beall, E. Fabbri, T. J. Schmidt, ACS Catal. 2021, 11, 3094.

[58] J. Zhou, L. Zhang, Y. C. Huang, C. L. Dong, H. J. Lin, C. Te Chen, L. H. Tjeng, Z. Hu, Nat. Commun. 2020, 11, 1984.

[59] B. Han, M. Risch, Y. L. Lee, C. Ling, H. Jia, Y. Shao-Horn, Phys. Chem. Chem. Phys. 2015, 17, 22576.

[60] M. Görlin, M. Gliech, J. F. De Araújo, S. Dresp, A. Bergmann, P. Strasser, Catal. Today 2016, 262, 65.

[61] W. T. Hong, M. Risch, K. A. Stoerzinger, A. Grimaud, J. Suntivich, Y. Shao-Horn, Energy Environ. Sci. 2015, 8, 1404

[62] L. Köhler, M. E. Abrishami, V. Roddatis, J. Geppert, M. Risch, ChemSusChem 2017, 10, 4479.

[63] D. K. Bediako, C. Costentin, E. C. Jones, D. G. Nocera, J. M. Savéant, J. Am. Chem. Soc. 2013, 135, 10492.

[64] M. S. Burke, L. J. Enman, A. S. Batchellor, S. Zou, S. W. Boettcher, Chem. Mater. 2015, 27, 7549.

[65] Q. Xu, H. Jiang, X. Duan, Z. Jiang, Y. Hu, S. W. Boettcher, W. Zhang, S. Guo, C. Li, Nano Lett. 2021, 21, 492.

[66] M. B. Stevens, L. J. Enman, A. S. Batchellor, M. R. Cosby, A. E. Vise, C. D. M. Trang, S. W. Boettcher, Chem. Mater. 2017, 29, 120.

[67] J. T. Mefford, A. R. Akbashev, M. Kang, C. L. Bentley, W. E. Gent, H. D. Deng, D. H. Alsem, Y. Yu, N. J. Salmon, D. A. Shapiro, P. R. Unwin, W. C. Chueh, Nature 2021, 593, 67.

[68] G. Schuck, I. Zisak, J. large-scale Res. Facil. 2020, 6, 139.

[69] A. Ankudinov, B. Ravel, Phys. Rev. B: Condens. Matter Mater. Phys. 1998, 58, 7565 . 